\title{
RELATION OF OWNER'S MANUALS TO SAFETY
}

\author{
S. David Leonard \\ Department of Psychology \\ University of Georgia \\ Athens, Georgia, USA \\ E-mail:dleonard@egon.psy.uga.edu
}

\begin{abstract}
Summary: Safe behavior is predicated on the individual's capability to perform appropriate acts when required. That capability involves both the requisite psychomotor skills and the knowledge of what acts are appropriate in the situation faced by the individual. Knowledge of the appropriate acts may be obtained in various ways. Among them are signs, verbal commands, instruction, and written materials. The present study examines the influence of one form of written materials associated with safe driving, that is, the owner's manual. Specifically, two surveys were performed to evaluate what use is made of the safety information in the manual and the awareness of the presence of safety information in the manual. The results suggested that owner's manuals are infrequently read, except for some specific sorts of information. Of all respondents in Experiment 1, only two indicated looking for safety information in the manual. Results of Experiment 2, suggested that respondents were aware of the possibility that safety information was in the manual, but there was little indication that it was used for that purpose. A possible approach to reaching more of the target population might be to produce a separate safety manual for owners and drivers.
\end{abstract}

\section{INTRODUCTION}

Safety is a paramount consideration in the human factors approach to automobile design and driving procedures. Design changes have increased safety in many ways, e.g. braking advances, use of running lights, and so on. However, many problems exist because of design flaws. For example, no standards have been adopted for location and for procedures for many important controls, such as those for the lights. Other operations that may be performed by the driver, such as turning on or modulating the operation of the heater or radio may require the driver to divert his or her view from the road. Further, lack of standardization can produce dangerous situations, if negative transfer causes a distracting event to occur. Performance in driving as in other activities requires both development of necessary skills and the knowledge of what skills should be employed at particular times. The information necessary may not be readily available to those who learned to drive before that information became necessary.

Over the years, owners' manuals have been provided with automobiles as a matter of course. They have generally become compendia of information that include numerous facts and many pages. Some such manuals exceed 300 pages in length. Owners are often admonished to read the manual before driving the vehicle. The individual who wishes to digest all the information has an imposing task, especially if he wishes to get home before dark. At the same time, changes in the capabilities and the procedures appropriate to take advantage of those 
capabilities have been important for safe driving. Individuals who learned to drive 20 or 30 years ago, and their numbers are legion, were likely taught to pump the brakes rapidly in certain situations. Certainly within the last ten years, most vehicles have been equipped with Automatic Braking Systems (ABS) for which such a maneuver is counterproductive. Further, some vehicles, especially the Sport Utility Vehicles (SUV) and four-wheel drive (4WD) vehicles may handle differently from other vehicles. Thus, the problem of negative transfer can influence driving capabilities and safety of both those drivers and others with whom they may intersect.

While ergonomists know negative transfer degrades performance on many mechanisms, including vehicles, the fact that many operators are unaware of the possibility of its occurrence exacerbates the problem. Information about changed procedures can be helpful in allowing individuals to practice appropriate behaviors under controlled conditions. How to get that information to the users is a significant problem. Clearly, use of mass media is one approach. Another possibility is through the owner's manual. Inasmuch as all vehicles are accompanied by such manuals at original sale, and the manuals are likely to remain with the vehicles upon resale, this is one means for providing accurate information about the specific vehicles. The purpose of the present studies was to evaluate how well information was obtained from these manuals. Two surveys were conducted. For purposes of clarity they will be called Experiments 1 and 2.

\section{EXPERIMENT 1}

As part of a broader examination of driver behavior a survey incorporated several items about the availability and use of owner's manuals. Availability of manuals for vehicles not purchased new is a factor in their use. How one reads the manual will be important in determining the usefulness of the manual. To assure one of getting all the important facts, it may be necessary to read the entire manual. However, this is a time-consuming task, and it was hypothesized many individuals might choose to look only for items that were of greatest interest at the moment.

\section{Method}

Respondents for the survey were obtained in three different states and included college students, some of whom received course credit for participating, and attendees at an elementary school carnival who received ride or raffle tickets for their cooperation. A total of 78 men and 150 women provided usable data. Data from an additional eight persons were discarded because they indicated that they had not received an owner's manual, and another four cases were discarded because they failed to indicate what they read in the manual.

Respondents were asked to indicate whether or not they received owner's manuals with their automobiles and what use they made of them. Specifically, they were asked what they read and given the choices of all the manual, reading until tired of it, reading for specific purposes, and other. If they responded that they read for specific purposes, they were asked to describe what those purposes were. Some of the information from this survey was included in a paper by Leonard and Karnes (2000). 


\section{Results and discussion}

Examination of the responses of men and women detected no reliable difference. Thus, for general data analysis those responses were combined. Analysis by age level did produce one statistically dependable result. As seen in Table 1, among those individuals aged 25 and older, 20 percent indicated they read the manual in its entirety, while only 7 percent of those younger than 25 stated that they read it all. This difference was dependable $\Pi^{2}(1)=7.97, p<.01$. A corresponding difference was found in responses to reading for special topics, in that the respondents under age 25 gave that response $65 \%$ of the time while only $54 \%$ of those 25 and older gave that response. No differences between those who had obtained the vehicle new and those who had obtained a used vehicle were statistically reliable. As noted earlier only eight respondents indicated they had not received a manual. Most of those owned older vehicles.

\section{Table 1}

Numbers of Responses about What Portions of Owner’s Manuals Are Read

\begin{tabular}{|c|c|c|c|c|c|}
\hline Respondents & $\underline{\text { All }}$ & None & $\begin{array}{l}\text { rts Read } \\
\text { Special }\end{array}$ & Until Tired & Total \\
\hline \multirow[t]{2}{*}{ Age 25+ } & $\overline{10}$ & 2 & 27 & 11 & 50 \\
\hline & $20 \%$ & $4 \%$ & $54 \%$ & $22 \%$ & \\
\hline \multirow[t]{2}{*}{ Age $<25$} & 12 & 13 & 115 & 38 & 178 \\
\hline & $7 \%$ & $7 \%$ & $65 \%$ & $21 \%$ & \\
\hline \multirow[t]{2}{*}{ Total } & 22 & 15 & 142 & 49 & 228 \\
\hline & $10 \%$ & $7 \%$ & $62 \%$ & $21 \%$ & \\
\hline
\end{tabular}

The responses of those indicating they read for specific topics are listed by topics in Table 2 . As may be seen more of the older respondents left the actual topic space blank, this result was statistically reliable $\Pi^{2}(1)=7.97, p<.01$. In addition, men were dependably more likely than women to indicate that they would look at topics involving maintenance $\Pi^{2}(1)=6.7, p<.01$, and women were more likely to express interest in the equipment $\Pi^{2}=7.26, p<.01$. In general, the equipment mentioned involved items such as the radio and the clock. 
Table 2

Topics in Owners’ Manuals Selected for Reading

\begin{tabular}{|c|c|c|c|c|c|c|c|c|c|}
\hline Respondents & Equip. & Maint. & Operations & $\underline{\text { Repairs }}$ & $\underline{\text { New Items }}$ & Safety & $\underline{\text { Blank }}$ & Other & $\underline{\text { Tota }}$ \\
\hline \multirow{2}{*}{ Men } & 3 & 20 & 4 & 7 & 1 & 1 & 15 & 1 & \\
\hline & $6 \%$ & $38 \%$ & $8 \%$ & $13 \%$ & $2 \%$ & $2 \%$ & $29 \%$ & $2 \%$ & \\
\hline \multirow[t]{2}{*}{ Women } & 19 & 19 & 13 & 9 & 3 & 1 & 19 & 7 & \\
\hline & $21 \%$ & $21 \%$ & $14 \%$ & $10 \%$ & $2 \%$ & $1 \%$ & $21 \%$ & $8 \%$ & \\
\hline \multirow[t]{2}{*}{ Age $25+$} & 5 & 7 & 2 & 1 & 0 & 0 & 12 & 0 & \\
\hline & $19 \%$ & $26 \%$ & $7 \%$ & $4 \%$ & $0 \%$ & $0 \%$ & $44 \%$ & $0 \%$ & \\
\hline \multirow[t]{2}{*}{ Age $<25$} & 17 & 32 & 15 & 15 & 4 & 2 & 22 & 8 & \\
\hline & $15 \%$ & $28 \%$ & $13 \%$ & $13 \%$ & $3 \%$ & $2 \%$ & $19 \%$ & $7 \%$ & \\
\hline
\end{tabular}

These results suggest the safety information contained in owner's manuals is not examined extensively. More extensive reading is reported by older respondents. Perhaps this is because they are more likely to be paying for the vehicle than are persons of normal college age. There is some suggestion in the data supporting population stereotypes indicating men are more concerned than women about mechanical matters in that they showed more interest in the maintenance of the vehicles. Only two respondents indicated they would look for safety topics in the manual. This could mean that there is little interest in safety, or it could simply mean that the respondents are not aware of any safety information included in the manuals.

\section{EXPERIMENT 2}

In order to evaluate the awareness of people about the safety information included in owner's manuals an additional survey was devised to examine how often individuals might use owner's manuals and how great the awareness of safety information availability might be.

\section{Method}

Respondents from the pool of students obtaining course credit for research participation at the University of Georgia provided responses to a short survey. Participants were 16 men and 16 women ranging from age18 to 25 with a median of 19. Most (24) of the respondents had received formal driving training, and the median years of driving experience was 3.5. The survey included questions about their vehicles, their knowledge about certain safety factors, and their information sources. They were also asked about their awareness of safety information in the owner's manual.

\section{Results and discussion}

The most common type of vehicles driven by the respondents were SUVs, 12, and compact cars, 11. Only eight respondents stated that they did not know or that there was no section in their owner's manuals regarding safety, but the other responses suggested that they had not spent much time looking at it. To the question of whether over inflation or under inflation 
would more likely cause the tire to overheat 10 males and 13 females stated that higher pressure was more likely to cause overheating. One female did not answer the question. Interestingly those individuals, particularly males, who drove SUVs were more likely to answer low pressure. The comparison using Yates correction factor of SUV drivers with all others produced $\Pi^{2}=9.10, \quad p<.01$. It is possible that the frequent discussions in the media of the problems with tire failures on SUVs could have concerned drivers of SUVs more than others.

When asked to provide possible reasons for a tire frequently losing air, most respondents gave an answer involving a puncture. Several simply said there was a leak. Only three responses could be interpreted as involving a defective tire, and they were not specific. It was assumed that with the publicity about tread separation, this might have been mentioned, but it was not. To a question asking why one's vehicle might bounce a bit, alignment (13 cases) and shock absorbers (12 cases) were common responses. Although some mentioned tires as a factor, the responses were such as old tires or bald tires. Only two responses even hinted at the possibility of tread separation.

In response to the request to rank the relevance of their safety sources, the highest ranking went to parents, next to driver training, then the media, followed by the owner's manual and automobile brochures. The primary sources for how much air to put in the tires were parents, followed by the owner's manuals and by the category of other. Many of those who responded "other" indicated they used the information on the tire. A telling result concerning the use of the owner's manual is the comparison of the rankings of sources of information about changing oil and tuning the car's radio. While the manual was mentioned as relevant for oil changes by only 18 respondents, who gave it an average rank of 2.0 in importance, 25 respondents mentioned the manual as a source of information about tuning the radio with an average rank of 1.5 .

\section{GENERAL DISCUSSION}

If you were to ask a safety professional how likely it is that an individual would read the owners manual upon getting an automobile, the answer would probably be "very low." The present data support that notion. Although the sample is not a national probability sample, it includes individuals who are reasonably intelligent and from rather disparate geographical areas. The fact that responses differ little suggests considerable generality of the results. Further, the results do not result from a lack of ability to read and understand the manuals nor are they biased by cultural conditions. It can be inferred from these surveys that the manual is recognized to be a source of information, but is infrequently used. Certainly the lack of safety information displayed by these respondents indicates failure to examine the manuals carefully. Some manufacturers have begun placing a number of warnings in one location in their manuals. However, if readers are not motivated to read those sections, they will get no benefit from them. The information obtained from the media may be useful, but it is difficult to insure that the appropriate information will be provided to a high percentage of the population.

An interesting feature of the responses is the fact that except for the tuning of the radio, parents are listed by college students as the primary source of information about automobiles. 
Unfortunately, as noted earlier, parents' knowledge may be 20 years old; therefore, they may be giving inadequate or even false information about some topics.

There are many problems involved in providing accurate safety information about vehicles, and evidence suggests that such information is often unknown as noted by Leonard and Karnes (1998). They found little difference as a function of whether or not the respondents had had a driver training course. Possibly, this is because of an emphasis in some courses on technique and development of skill. Completing a safety unit as a requirement for completing the course might change that. The fact that safe procedures may change with vehicle changes requires providing the appropriate information to the users. On vehicle warnings may help, but as some have noted, too many warnings may reduce effectiveness (cf. Frantz et al, 1999). One approach to consider is giving a separate manual with vehicles that would be presented as involving the new features of the vehicles and that would include safety information. The effectiveness of such a procedure would need to be tested, but it might be worth trying.

\section{REFERENCES}

Frantz, J.P., Rhoades, T. P., Young. S.L., \& Schiller, JA. (1999). Potential problems associated with overusing warnings. Proceedings of the Human Factors Society $43^{\text {nd }}$ Annual Meeting -1999, Santa Monica, CA: Human Factors Society, 916-920.

Leonard, S.D., \& Karnes, E.W. (1998). Perception of risk in automobiles: Is it accurate. Proceedings of the Human Factors Society $42^{\text {nd }}$ Annual Meeting-1998, Santa Monica, CA: Human Factors Society, 1083-1087.

Leonard, S.D., \& Karnes, E.W. (2000). Compatibility of safety and comfort in vehicles. In Proceedings of the 13th Triennial Congress of the International Ergonomics Association v. 3, 357-360. 